\title{
Photochemistry of 1-phenyl-tetrazolone isolated in solid argon
}

\author{
A. Gómez-Zavaglia ${ }^{\text {a,b }}$, I.D. Reva ${ }^{\text {a }}$, L. Frija ${ }^{c}$, M.L. Cristiano ${ }^{c}$, R. Fausto ${ }^{a}{ }^{*}$ \\ ${ }^{a}$ Department of Chemistry, Faculty for Sciences and Technology, R. Larga, P-3004-535 Coimbra, Unniversity of Coimbra, Portugal \\ ${ }^{\mathrm{b}}$ Facultad de Farmacia y Bioquímica, Universidad de Buenos Aires, Argentina \\ ${ }^{\mathrm{c}}$ Department of Chemistry and Biochemistry, University of Algarve, Faro, Portugal
}

Received 28 June 2005; received in revised form 12 August 2005; accepted 13 August 2005

Available online 26 September 2005

\begin{abstract}
The molecular structure, vibrational spectra, tautomerism and photochemistry of the derivative of tetrazole, 1-phenyl-tetrazolone $\left(\mathrm{C}_{7} \mathrm{H}_{6} \mathrm{~N}_{4} \mathrm{O}\right.$; PT) have been studied by FT-IR matrix isolation spectroscopy and DFT/B3LYP/6-311++G(d,p) calculations. Among the five structures in which PT could be expected to exist (two keto tautomers, one mesoionic olate-form and two different conformers of the hydroxyl tautomer), only the most stable species, 1-phenyl-1,4-dihydro-5H-tetrazol-5-one, could be experimentally observed in low temperature argon matrices. Monomers of this tautomer give rise to an IR spectrum that fits nicely the calculated spectrum obtained at the DFT/B3LYP/6-311++G(d,p) level of theory. In situ UV irradiation $(\lambda>235 \mathrm{~nm})$ of the matrix-isolated PT induces three main photochemical processes, all of them involving cleavage of the tetrazole ring: e.g. (1) molecular nitrogen loss, with production of 1-phenyl-diaziridin-3-one; this compound reacts subsequently to form 1-aza-1,2,4,6cycloheptatetraene and isocyanic acid (eventually, also to form CO plus phenyldiazene); (2) cleavage of the $\mathrm{C}_{(5)}-\mathrm{N}_{(1)}$ and $\mathrm{N}_{(3)}-\mathrm{N}_{(4)}$ tetrazole-ring bonds, with production of phenylazide and isocyanic acid, with phenylazide then losing $\mathrm{N}_{2}$ to yield as final product 1-aza-1,2,4,6-cycloheptatetraene; and (3) cleavage of the $\mathrm{N}_{(1)}-\mathrm{N}_{(2)}$ and $\mathrm{N}_{(4)}-\mathrm{C}_{(5)}$ tetrazole-ring bonds, to yield phenylisocyanate and azide. The observed photochemical processes are distinct from the preferred thermal fragmentation channel, where $\mathrm{CO}$ is produced together with a weak IR absorbant species.
\end{abstract}

(C) 2005 Elsevier B.V. All rights reserved.

Keywords: 1-Phenyl-tetrazolone; 1-Aza-1,2,4,6-cycloheptatetraene; Phenyldiazene; Phenylisocyanate; Azide; Isocyanic acid; Phenylazide; 1-Phenyl-1,2dihydrotetrazete; Tetrazole-ring cleavage; Matrix isolation IR spectroscopy; DFT/B3LYP; 6-311++G(d,p) calculations; Photochemical fragmentation

\section{Introduction}

The relevance of tetrazolic compounds is widespread because of their applications in fields such as agriculture (as pesticides) and medicine (as antihypertensive, antialergic, antibiotic and anticonvulsant agents and also in cancer and AIDS treatments) [1-8]. Most of their applications are related with the acid/base properties of the tetrazolic ring. In fact, the tetrazolic acid fragment, $-\mathrm{CN}_{4} \mathrm{H}$, has similar acidity to the carboxylic acid group, $-\mathrm{CO}_{2} \mathrm{H}$, and is almost isosteric with it, but is metabolically more stable at physiologic $\mathrm{pH}[9]$.

The metabolic stability of the tetrazole ring also strongly influences applications of its derivatives, including those containing the 5-oxy-substituent (tetrazolones). As a matter of fact, tetrazolone derivatives have been used as potent and selective

\footnotetext{
* Corresponding author. Tel.: +351239 852080; fax: +351 239827703.

E-mail addresses: angoza@qui.uc.pt (A. Gómez-Zavaglia), rfausto@ci.uc.pt (R. Fausto).
}

agonists of the $\beta 3$ human adrenergic receptors ( $\beta 3$-HAR) [10-13]. The receptor is linked to the increase in metabolic rates in humans and, thus, $\beta 3$-HAR agonists are useful in the treatment of obesity. Other $\beta 3$-HAR agonists, containing imidazolidinone and imidazolone rings, were found to have quite low oral bioavailability due to their extensive metabolism. The higher stability of tetrazolone derivatives allowed to overcome this problem [10-13].

The use of tetrazole derivatives, including tetrazolones, in photography and photoimaging has also been claimed by different patents [14]. In addition, tetrazolones have been used in inflating passenger restraint gas inflator bags [15].

From a more fundamental point of view, tetrazolones are also very interesting molecules, because they may exhibit different tautomers [16-23] and might be expected to have a very rich photochemistry [24-27]. Tautomerism has been found to be important in the tetrazole family in general. Indeed, unsubstituted tetrazole itself exhibits tautomerism, occurring exclusively as its $1 \mathrm{H}$-tautomer in the crystalline phase and mostly as its $2 \mathrm{H}$ tautomer in the gaseous phase $(\sim 90 \%$ of the total population 
at $90^{\circ} \mathrm{C}$ ); in solution, both tautomers coexist, with the population of the most polar $1 H$-form increasing with the polarity of the solvent [19-23]. In the case of substituted tetrazoles, tautomerism may also involve the substituent groups, as it was found, for example, in the cases of 1-methyl-tetrazol-5-thione and 2-methyl-tetrazol-5-amine [28,29].

The photochemistry of tetrazole and some of the above mentioned substituted tetrazoles has been addressed elsewhere [24,26-30]. Tetrazole-ring cleavages, leading either to azides or aziridines, represent the main characteristic photochemical reactions of this family of compounds [24-30]. In spite of that, the nature of the substituent strongly determines the precise nature and relative amount of the final photoproducts, then making this type of compounds a permanent challenge to investigation [24,26-30].

The use of matrix isolation technique, coupled to a suitable probing method (e.g., FT-IR spectroscopy), represents an appropriate approach to improve our understanding of the photochemistry of tetrazole derivatives, because it introduces a useful simplification for the study of the mechanisms of reaction. Indeed, for the matrix-isolated compound, different photochemical pathways can be easily foreseen, since the processes are essentially cage-confined (molecular diffusion is inhibited except when very small species are produced). Hence, taking advantage of the unique capabilities of the matrix-isolation/FTIR technique, and in the continuation of our ongoing research program on the photochemistry of tetrazole derivatives [28,29], we now present the results of our studies on 1-phenyl-tetrazolone (PT). Besides the structural and vibrational characterization of the matrix-isolated monomers of the compound, the photochemical processes it undergoes upon broad band UV irradiation $(\lambda>235 \mathrm{~nm})$ were investigated. The interpretation of the experimental results was supported by extensive DFT calculations and, whenever available, also by previously reported reference matrix-isolation data on the putative photoproducts of PT.

\section{Materials and methods}

\subsection{Infrared spectroscopy}

PT was synthesized as described elsewhere [31,32]. The IR spectra were obtained using a Mattson (Infinity 60AR Series) Fourier transform infrared spectrometer, equipped with a deuterated triglycine sulphate (DTGS) detector and a $\mathrm{Ge} / \mathrm{KBr}$ beamsplitter, with $0.5 \mathrm{~cm}^{-1}$ spectral resolution. Necessary modifications of the sample compartment of the spectrometer were done in order to accommodate the cryostat head and allow purging of the instrument by a stream of dry nitrogen to remove water vapors and $\mathrm{CO}_{2}$. A solid sample of PT was placed in a specially designed doubly termostattable Knudsen cell [33]. The sample container was maintained at $369 \mathrm{~K}$ and valve nozzle was kept at a slightly higher temperature $(380 \mathrm{~K})$. Matrices were prepared by co-deposition of PT vapors coming out of the Knudsen cell, together with large excess of the matrix gas (argon N60, obtained from Air Liquide), onto the CsI substrate of the cryostat cooled to $10 \mathrm{~K}$. Care was taken to keep the guest-to-host ratio in matrices low enough to avoid association. All experiments were performed using an APD Cryogenics closed-cycle helium refrigeration system with a DE-202A expander.

Irradiation of the samples was carried out with a $150 \mathrm{~W}$ xenon arc lamp (Osram XBO 150W/CR OFR) through the outer $\mathrm{KBr}$ window of the cryostat $(\lambda>235 \mathrm{~nm})$.

\subsection{Computational methodology}

The quantum chemical calculations for PT were performed with Gaussian 98 [34] at the DFT level of theory, using the 6-311++G(d,p) basis set and the three-parameter density functional abbreviated as B3LYP, which includes Becke's gradient exchange correction [35] and the Lee, Yang, Parr correlation functional [36]. The calculations on the possible photoproducts were carried out at the same level of theory.

Geometrical parameters of the considered structures were optimized using the geometry direct inversion of the invariant subspace (GDIIS) method [37]. In order to assist the analysis of the experimental spectra, vibrational frequencies and IR intensities were also calculated with the same basis set. The computed harmonic frequencies were scaled down by a single factor (0.978) to correct them for the effects of basis set limitations, neglected part of electron correlation and anharmonicity effects. Normal coordinate analysis was undertaken in the internal coordinates space, as described by Schachtschneider [38], using the program BALGA and the optimized geometries and harmonic force constants resulting from the DFT/B3LYP/6-311++G(d,p) calculations.

\section{Results and discussion}

\subsection{DFT structural calculations: tautomerism and molecular geometries}

As it was mentioned in the Section 1, tetrazole compounds usually exist in different tautomeric forms. Recently, we have studied the tautomerism in some related compounds (e.g., 1-methyl-tetrazol-5-thione and 2-methyl-tetrazol-5-amine $[28,29])$. The compound now studied is related with 1-methyltetrazol-5-thione in the sense that the positions of the substituents are the same (in PT, the thioketo group is replaced by the keto group and the methyl group, by the phenyl group). According to the DFT/B3LYP/6-311++G(d,p) calculations, PT can exist in five tautomeric forms, which may be considered as "equivalent" to the five tautomers found for 1-methyl-tetrazol5-thione [29]: two keto tautomers, one mesoionic olate form and two hydroxy conformers (Fig. 1). Two of these species (the most stable keto form and the olate tautomer) are planar structures, belonging to the $\mathrm{C}_{\mathrm{S}}$ symmetry point group, whereas the remaining three forms are non-planar structures $\left(\mathrm{C}_{1}\right.$ point group $)$.

The 1-phenyl-tetrazolone keto tautomer 1-phenyl-1,4dihydro- $5 \mathrm{H}$-tetrazol-5-one was predicted to be considerably more stable than all the remaining species. Part of the stabilization of this form results from the favorable interactions between the phenyl hydrogen atoms ortho to the tetrazole ring, $\mathrm{H}_{(12)}$ and $\mathrm{H}_{(16)}$, and the $\mathrm{N}_{(2)}$ and carbonyl oxygen atoms, respectively 




1-phenyl -1,4-dihydro-5H-tetrazol-5-one $E=-564.7010443 \mathrm{~kJ} \mathrm{~mol}^{-1}$ $\mathrm{C}_{\mathrm{s}} ; \Delta \mathrm{E}=0.0 ; \mu=0.45 \mathrm{D}$

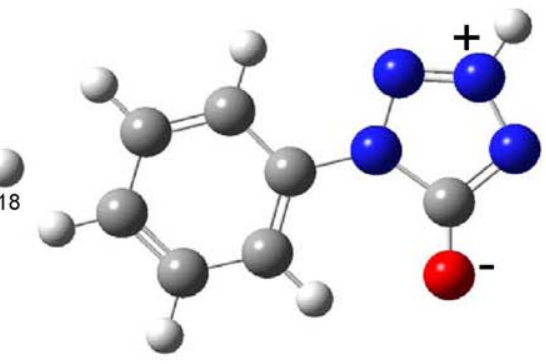

1-phenyl -1 H-tetrazol-3 ium-5-olate $\mathrm{C}_{\mathrm{s}} ; \Delta \mathrm{E}=60.7 \mathrm{~kJ} \mathrm{~mol}^{-1} ; \mu=4.89 \mathrm{D}$

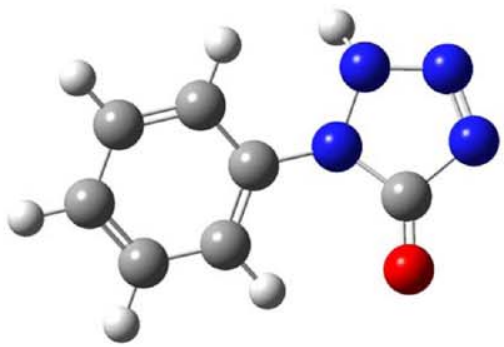

1-phenyl 1,2-dihydro-5H-tetrazol-5-one $\mathrm{C}_{1} ; \Delta \mathrm{E}=91.9 \mathrm{~kJ} \mathrm{~mol}^{-1} ; \mu=6.23 \mathrm{D}$

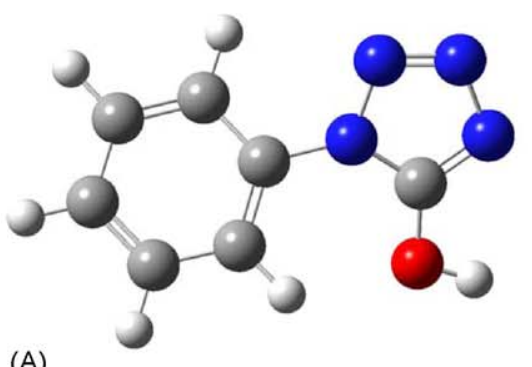

$(A)$

$$
\begin{aligned}
& \text { 1-phenyl-1 H-tetrazol-5-ol } \\
& \Delta \mathrm{E}=50.1 \mathrm{~kJ} \mathrm{~mol}^{-1} ; \mu=5.04
\end{aligned}
$$

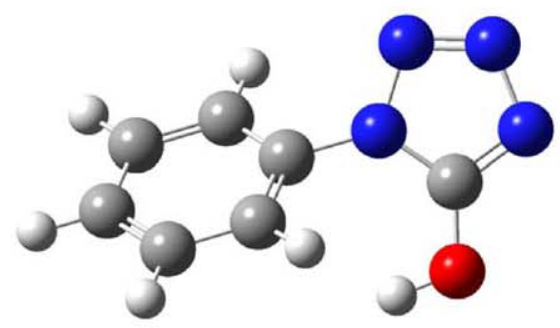

(B)

Fig. 1. Tautomers of 1-phenyltetrazolone (PT) with atom numbering. Symmetry point groups and dipole moments and relative energies (including zero point vibrational energies) calculated at the B3LYP/6-311++G(d,p) level of theory are also given.

(see Fig. 1). These interactions also partially justify the fact that the two rings (phenyl and tetrazole) stay in the same plane. The second most stable form is one of the two hydroxy forms (conformer A of 1-phenyl-1H-tetrazol-5-ol; Fig. 1) and has an energy higher than the most stable species by ca. $50 \mathrm{~kJ} \mathrm{~mol}^{-1}$. In this hydroxy conformer, the hydroxylic hydrogen atom points to the opposite direction relatively to the phenyl group, whereas in the higher energy hydroxy conformer (form B, with relative energy of ca. $70 \mathrm{~kJ} \mathrm{~mol}^{-1}$ ) this hydrogen atom and the phenyl group point nearly to each other. In conformer A, the optimization of the interaction between $\mathrm{H}_{(16)}$ and the hydroxylic oxygen atom (which contrarily to the carbonyl oxygen in the most stable keto tautomer has its lone-electron pairs out of the plane of the tetrazole ring) is responsible for the deviation of the molecule from planarity. According to the calculations, the $\mathrm{C}_{(11)}=\mathrm{C}_{(6)}-\mathrm{N}_{(1)}-\mathrm{C}_{(5)}$ inter-ring dihedral angle in this molecule is $30.3^{\circ}$. On the other hand, in conformer $\mathrm{B}$, a strong steric interaction between $\mathrm{H}_{(16)}$ and the hydroxylic hydrogen atom takes place and leads to a much larger deviation of the molecule from planarity, the $\mathrm{C}_{(11)}=\mathrm{C}_{(6)}-\mathrm{N}_{(1)}-\mathrm{C}_{(5)}$ inter-ring dihedral angle being predicted by the calculations as $52.2^{\circ}$.

The second keto tautomer and the olate form differ from the most stable tautomer essentially in the position of the tetrazolering hydrogen atom. The olate tautomer is predicted by the calculations as the third most stable form, with a relative energy of ca. $60 \mathrm{~kJ} \mathrm{~mol}^{-1}$. Like the most stable tautomer, the olate form has a planar structure, since in this case the stabiliza- tion of the planar geometry resulting from favorable interactions between the phenyl hydrogen atoms ortho to the tetrazole ring, $\mathrm{H}_{(12)}$ and $\mathrm{H}_{(16)}$, and the $\mathrm{N}_{(2)}$ and oxygen atoms, do also take place. On the other hand, the second keto tautomer, 1-phenyl1,2-dihydro-5 $H$-tetrazole-5-one (Fig. 1), is non-planar, with an inter-ring dihedral angle of $34.2^{\circ}$ and the nitrogen atom bearing the hydrogen atom considerably pyramidalized (the calculated $\mathrm{N}_{(1)}-\mathrm{N}_{(2)}-\left(\mathrm{H}_{(18)}\right)-\mathrm{N}_{(3)}$ dihedral angle is $\left.129.9^{\circ}\right)$, due to the proximity between the hydrogen atom bonded to the tetrazole ring and $\mathrm{H}_{(12)}$. This form corresponds to the highest energy tautomer, with a relative energy of ca. $92 \mathrm{~kJ} \mathrm{~mol}^{-1}$.

The fully optimized geometries for all TP tautomers are provided as Supporting Information (Table S1).

\subsection{IR spectrum of the matrix isolated compound (as-deposited matrix)}

Considering the relative energies of the five tautomers of PT, only the most stable form is expectable to be present in the gaseous phase and trapped in the low temperature matrices. Indeed, the IR spectrum of the as-deposited PT Ar-matrix nicely fits the calculated spectrum of 1-phenyl-1,4-dihydro- $5 \mathrm{H}$ tetrazol-5-one (Fig. 2). Table 1 displays the proposed band assignments. (Table S2, Supporting Information) shows the definition of the internal coordinates used to perform the normal coordinate analysis made in this study, which is presented in Table S3. 

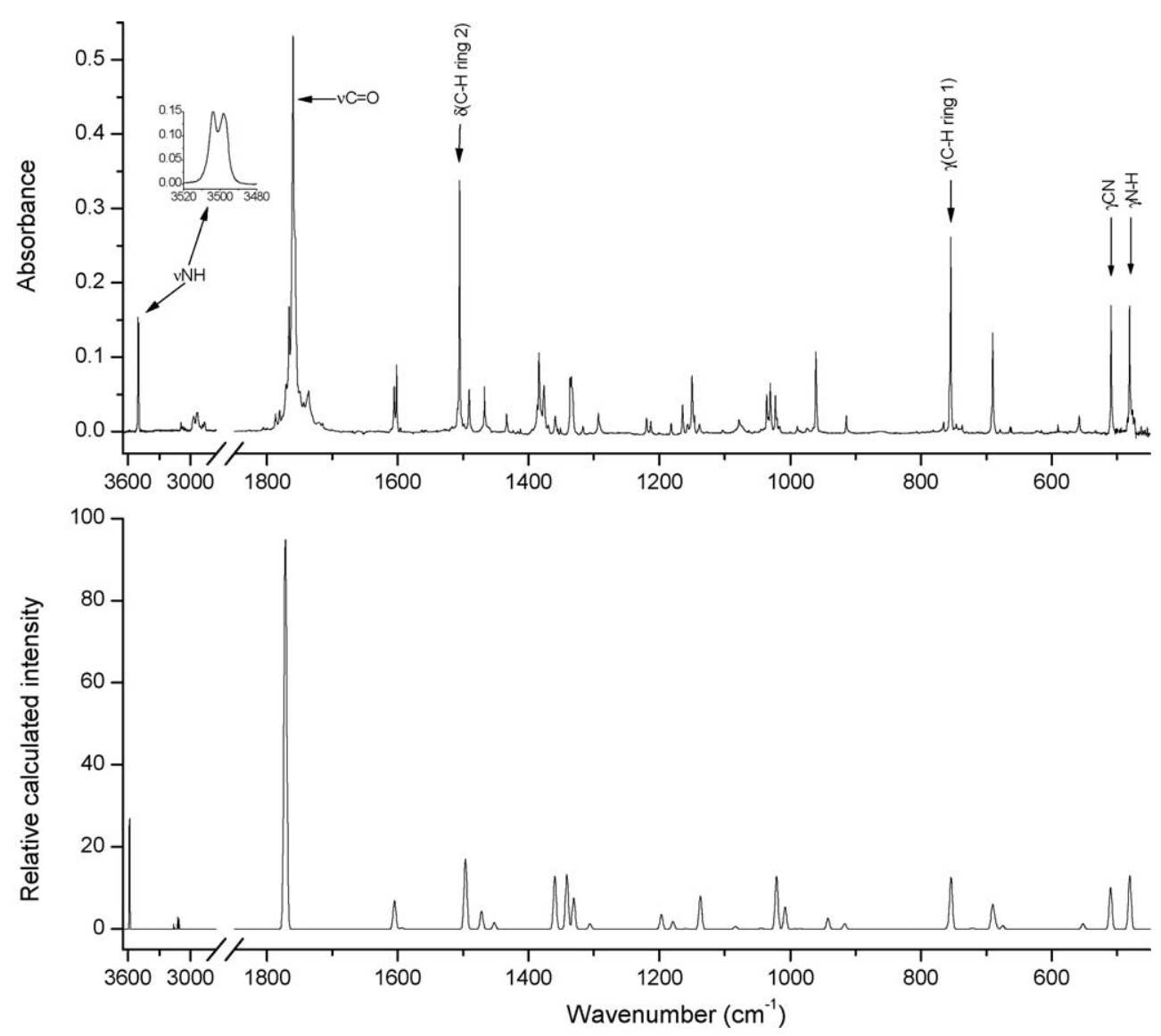

Fig. 2. Infrared spectra of PT: upper panel, isolated in an argon matrix (as-deposited matrix; substrate temperature, $10 \mathrm{~K}$; nozzle temperature, $369 \mathrm{~K}$; bands due to traces of monomeric water subtracted). Lower panel, DFT/B3LYP/6-311++G(d,p) calculated spectrum for the minimum energy conformation. Calculated spectra were simulated using Gaussian functions centered at the calculated (scaled by 0.978 ) frequency and with bandwidth at half height equal to $5 \mathrm{~cm}^{-1}$.

It can be observed in Fig. 2 that most of the bands in the experimental spectrum appear split due to existence of different matrix sites. Extensive site splitting has also been observed previously for other tetrazoles isolated in argon matrices [16,17,28,29]. The most intense bands of the PT spectrum are due to the $\nu \mathrm{N}-\mathrm{H}$, $\nu \mathrm{C}=\mathrm{O}, \delta(\mathrm{C}-\mathrm{H}$ ring 2$), \gamma(\mathrm{C}-\mathrm{H}$ ring 1$), \gamma \mathrm{CN}$ and $\gamma \mathrm{N}-\mathrm{H}$ modes.

The $\nu \mathrm{N}-\mathrm{H}$ vibration gives rise to a triplet of bands, at 3503.9, 3498.2 and $3496.9 \mathrm{~cm}^{-1}$, indicating that the local environment around the NH group in the various possible matrix sites occupied by the PT molecule in the argon matrix can be essentially of three different types. This fact is reinforced by the observation that the $\delta \mathrm{NH}$ mode does also give rise to a triplet of bands near $1335 \mathrm{~cm}^{-1}$. On the other hand, the $\gamma \mathrm{NH}$ mode gives rise to only one main band, at $481.0 \mathrm{~cm}^{-1}$, pointing to a similar intermolecular potential for out-of-plane deformation of the tetrazole-ring hydrogen atom in all three main matrix sites. These results can also be correlated with the planarity of the guest molecule, which can fit into a single layer of closely packed argon atoms (implying similar stacking interactions), but with mismatching longitudinal environments.

The most intense band corresponds to the $\nu \mathrm{C}=\mathrm{O}$ vibrational mode and appears as a group of, at least, nine bands. It has approximately the third part of the whole area under the spectrum $(31 \%)$, in good consonance with the theoretical predictions $(34 \%)$.
The $\delta(\mathrm{C}-\mathrm{H}$ ring 2$)$ vibrational mode corresponds to the symmetric (relatively to a plane perpendicular to the phenyl-ring passing through $\mathrm{C}_{(6)}$ and $\mathrm{C}_{(9)}$ ) bending mode of the four phenyl hydrogen atoms placed at the ortho and meta positions relatively to the tetrazole fragment. The calculated intensity for this vibrational mode is similar in PT $\left(90.7 \mathrm{~km} \mathrm{~mol}^{-1}\right)$ and in 1-phenyltetrazole $\left(82.1 \mathrm{~km} \mathrm{~mol}^{-1}\right.$ [39]), but nearly twice those found in 5-chloro-1-phenyltetrazole $\left(57.5 \mathrm{~km} \mathrm{~mol}^{-1}\right.$ [39]) and chlorobenzene $\left(45.5 \mathrm{~km} \mathrm{~mol}^{-1}\right)$, being much more intense than in other monosubstituted phenyl compounds, such as for example benzil or 1-phenyl-1,2-propanedione [40,41] (in benzil the $\delta(\mathrm{C}-\mathrm{H}$ ring 2$)$ asym and $\delta(\mathrm{C}-\mathrm{H}$ ring 2$)$ sym modes are predicted to give rise to bands with intensity equal to 0.9 and $0.7 \mathrm{~km} \mathrm{~mol}^{-1}$, respectively [40]; in 1-phenyl-1,2-propanedione, the predicted intensity for this mode is $0.6 \mathrm{~km} \mathrm{~mol}^{-1}$ [41]). These results indicate that this vibration is very sensitive to substituent effects. On the other hand, it does not appear to be very sensitive to matrix local environment, since for the above compounds existing in more than one site in argon matrices it has been systematically observed as a single band [39-41]. Very interestingly, this is just the opposite situation compared to $\gamma(\mathrm{C}-\mathrm{H}$ ring1), whose calculated intensity in PT $\left(66.7 \mathrm{~km} \mathrm{~mol}^{-1}\right)$ does not differ very much from those found in other phenyl monosubstituted molecules (e.g., 1-phenyltetrazole, $44.1 \mathrm{~km} \mathrm{~mol}^{-1}$; 5chloro-1-phenyltetrazole, $35.1 \mathrm{~km} \mathrm{~mol}^{-1}$ [39], chlorobenzene, 
Table 1

Observed frequencies $\left(\mathrm{cm}^{-1}\right)$ for PT in argon matrices ${ }^{\mathrm{a}}$

\begin{tabular}{|c|c|c|c|c|}
\hline Approximate Description & Calculated frequency & Intensity & Observed Frequency $\operatorname{Ar}(10 \mathrm{~K})$ & I \\
\hline$v \mathrm{~N}-\mathrm{H}$ & 3585.7 & 144.1 & $3503.9 / 3498.2 / 3496.9$ & $\mathrm{~S} / \mathrm{S} / \mathrm{sh}$ \\
\hline$\nu(\mathrm{C}-\mathrm{H}$ ring 2$)$ & 3159.7 & 6.7 & $3090.3 / \sim 3077$ & $\mathrm{w} / \mathrm{w}$ \\
\hline$\nu(\mathrm{C}-\mathrm{H}$ ring 1$)$ & 3149.3 & 0.3 & $3059.0 / 3049.4$ & $\mathrm{w} / \mathrm{w}$ \\
\hline$\nu(\mathrm{C}-\mathrm{H}$ ring 3$)$ & 3122.3 & 15.1 & $2970.6 / 2935.3$ & $\mathrm{w} / \mathrm{w}$ \\
\hline$\nu(\mathrm{C}-\mathrm{H}$ ring 4$)$ & 3110.4 & 13.3 & $2883.7 / 2862.9$ & $\mathrm{w} / \mathrm{w}$ \\
\hline$\nu(\mathrm{C}-\mathrm{H}$ ring 5$)$ & 3100.2 & $<0.1$ & n.o. & \\
\hline$\nu \mathrm{C}=\mathrm{O}$ & 1771.7 & 507.8 & $\begin{array}{l}1786.8 / 1780.7 / 1770.7 / \\
1765.9 / 1759.7 / 1757.1 / \\
1749.7 / 1744.0 / 1736.1\end{array}$ & $\begin{array}{l}\mathrm{w} / \mathrm{w} / \mathrm{w} / \\
\mathrm{w} / \mathrm{S} / \mathrm{sh} / \\
\mathrm{m} / \mathrm{w} / \mathrm{w}\end{array}$ \\
\hline$\nu(\mathrm{C}-\mathrm{C}$ ring 2$)$ & 1604.8 & 36.6 & $1605.6 / 1601.6$ & $\mathrm{~m} / \mathrm{m}$ \\
\hline$\nu(\mathrm{C}-\mathrm{C} \operatorname{ring} 4)$ & 1593.9 & 1.6 & $1595.9 / 1593.3$ & $\mathrm{~m} / \mathrm{w}$ \\
\hline$\delta(\mathrm{C}-\mathrm{H}$ ring 2$)$ & 1496.3 & 90.7 & 1505.2 & $\mathrm{~S}$ \\
\hline$\nu \mathrm{N}=\mathrm{N}$ & 1471.8 & 23.5 & 1490.8 & $\mathrm{~m}$ \\
\hline$\delta(\mathrm{C}-\mathrm{H} \operatorname{ring} 3)$ & 1452.3 & 8.2 & 1467.4 & $\mathrm{~m}$ \\
\hline$\nu \mathrm{N}-\mathrm{C}$ (inter ring) & 1359.7 & 68.6 & $\begin{array}{l}1386.6 / 1384.0 / \\
1376.4 / 1369.9 / 1359.4\end{array}$ & $\begin{array}{l}\mathrm{w} / \mathrm{m} \\
\mathrm{m} / \mathrm{w} / \mathrm{w}\end{array}$ \\
\hline$\delta \mathrm{NH}$ & 1341.3 & 70.8 & $1336.5 / 1334.8 / 1333.3$ & $\mathrm{~m} / \mathrm{m} / \mathrm{sh}$ \\
\hline$\delta(\mathrm{C}-\mathrm{H} \operatorname{ring} 1)$ & 1330.8 & 40.1 & $1320.1 / 1316.6$ & $\mathrm{w} / \mathrm{w}$ \\
\hline$\nu(\mathrm{C}-\mathrm{C} \operatorname{ring} 3)$ & 1306.1 & 6.9 & 1293.2 & $\mathrm{~m}$ \\
\hline$\nu \mathrm{N}-\mathrm{C}$ & 1196.9 & 19.0 & $1219.4 / 1213.0 / 1200.8$ & w/w/w \\
\hline$\delta(\mathrm{C}-\mathrm{H} \operatorname{ring} 4)$ & 1179.2 & 9.7 & 1188.6/1181.8 & $\mathrm{w} / \mathrm{w}$ \\
\hline$\delta(\mathrm{C}-\mathrm{H}$ ring 5$)$ & 1159.5 & 0.8 & 1171.0 & w \\
\hline$\nu \mathrm{N}-\mathrm{N}(1,2)$ & 1137.3 & 42.7 & $\begin{array}{l}\text { 1164.6/1156.2/1149.8/ } \\
/ 1146.1 / 1138.9\end{array}$ & $\begin{array}{l}\mathrm{m} / \mathrm{w} / \mathrm{m} \\
\mathrm{w} / \mathrm{w}\end{array}$ \\
\hline$\nu(\mathrm{C}-\mathrm{C}$ ring 6$)$ & 1083.5 & 3.5 & $1078.2 / 1074.3$ & $\mathrm{w} / \mathrm{w}$ \\
\hline$\nu(\mathrm{C}-\mathrm{C} \operatorname{ring} 5)$ & 1044.3 & 1.3 & 1044.9 & w \\
\hline$\nu \mathrm{N}-\mathrm{N}(3,4)$ & 1020.7 & 68.1 & $1035.8 / / 1030.3$ & $\mathrm{~m} / \mathrm{m}$ \\
\hline$\delta(\operatorname{ring} 1)$ & 1007.7 & 28.6 & $1022.4 / 1019.9 / 1010.3$ & $\mathrm{~m} / \mathrm{m} / \mathrm{w}$ \\
\hline$\nu(\mathrm{C}-\mathrm{C}$ ring 1$)$ & 992.6 & 0.4 & 1000.3 & w \\
\hline$\gamma(\mathrm{C}-\mathrm{H}$ ring 5) & 984.7 & 0.6 & 989.0/984.1 & $\mathrm{w} / \mathrm{w}$ \\
\hline$\tau($ ring 3$)$ & 971.5 & $<0.1$ & $974.6 / 972.4$ & $\mathrm{w} / \mathrm{w}$ \\
\hline$\nu \mathrm{C}-\mathrm{N}$ & 942.2 & 14.2 & 960.6 & $\mathrm{~m}$ \\
\hline$\gamma(\mathrm{C}-\mathrm{H}$ ring 3$)$ & 916.6 & 7.4 & 914.2 & $\mathrm{~m}$ \\
\hline$\gamma(\mathrm{C}-\mathrm{H}$ ring 2$)$ & 838.2 & $<0.1$ & n.o. & \\
\hline$\delta($ Nring 1$)$ & 758.5 & 2.2 & 765.3 & w \\
\hline$\gamma(\mathrm{C}-\mathrm{H}$ ring 1$)$ & 754.0 & 66.7 & $756.1 / 754.6 / 752.2$ & $\mathrm{Sh} / \mathrm{S} / \mathrm{w}$ \\
\hline$\gamma \mathrm{C}=\mathrm{O}$ & 721.7 & 1.4 & 736.8 & w \\
\hline$\tau($ ring 1$)$ & 690.6 & 30.4 & 690.5 & $\mathrm{~m}$ \\
\hline$\delta(\operatorname{ring} 3)$ & 686.6 & 9.1 & 680.6 & w \\
\hline$\tau($ Nring 1$)$ & 675.1 & 4.7 & 679.0 & w \\
\hline$\delta(\operatorname{ring} 2)$ & 617.0 & 0.2 & 612.4 & w \\
\hline$\delta \mathrm{C}=\mathrm{O}$ & 552.3 & 7.0 & 558.0 & w \\
\hline$\gamma \mathrm{CN}$ & 510.0 & 54.1 & $509.4 / 508.4$ & $\mathrm{msh}$ \\
\hline$\gamma \mathrm{N}-\mathrm{H}$ & 480.7 & 69.3 & $\begin{array}{l}484.1 / 481.0 / 478.9 \\
476.2\end{array}$ & $\begin{array}{l}\mathrm{w} / \mathrm{m} / \mathrm{w} \\
\mathrm{w}\end{array}$ \\
\hline$\gamma(\mathrm{C}-\mathrm{H}$ ring 4$)$ & 408.4 & $<0.1$ & n.i. & \\
\hline$\delta \mathrm{CN}$ & 371.4 & 0.6 & & \\
\hline$\delta($ Nring 2) & 318.6 & 6.3 & & \\
\hline$\tau($ ring 2$)$ & 286.5 & 0.8 & & \\
\hline$\tau($ Nring2) & 218.1 & 1.8 & & \\
\hline$\delta \mathrm{NC}$ & 173.7 & 1.5 & & \\
\hline$\gamma \mathrm{NC}$ & 97.7 & 2.9 & & \\
\hline$\tau \mathrm{C}-\mathrm{N}$ & 24.0 & $<0.1$ & & \\
\hline
\end{tabular}

DFT/B3LYP/6-311++G(d,p) calculated frequencies and intensities $\left(\mathrm{km} \mathrm{mol}^{-1}\right)$ are given for comparison. See Table S2 for definition of internal coordinates.

a I, intensity; S, strong; m, medium; w, weak, sh, shoulder; n.o., not observed; n.i., not investigated. $v$, bond stretching, $\delta$, bending, $\gamma$, rocking, $\tau$, torsion.

$62.7 \mathrm{~km} \mathrm{~mol}^{-1}$; benzil, 38.6 and $50.2 \mathrm{~km} \mathrm{~mol}^{-1}$, for the antisymmetric and symmetric mode, respectively [40]; terphenyl, $75.2 \mathrm{~km} \mathrm{~mol}^{-1}$ [42]), but are usually observed as a site-split multiplet (i.e., this mode seems to be relatively little affected by substitution, but it is quite sensitive to the matrix local environment).
The remaining intense band in the spectrum of PT is due to the $\gamma \mathrm{CN}$ coordinate, which corresponds to the out of plane vibration leading to pyramidalization of $\mathrm{N}_{(1)}$. This band is observed around $500 \mathrm{~cm}^{-1}$, at a position similar to those found for the equivalent vibrations in other 1-phenyl-substituted tetrazoles [39]. In both 1-phenyltetrazole and 5-chloro-1-phenyltetrazole 
[39] the $\gamma \mathrm{CN}$ band was found to be less intense than in PT (calculated intensities are ca. 10 in these two compounds, versus $55 \mathrm{~km} \mathrm{~mol}^{-1}$ in PT). This result is consistent with a higher degree of polarization of the $\mathrm{C}_{(5)}-\mathrm{N}_{(1)}$ bond in PT due to the presence of the oxygen substituent linked to $\mathrm{C}_{(5)}$, and can also be correlated with the considerably longer $\mathrm{C}_{(5)}-\mathrm{N}_{(1)}$ bond length $(140.0 \mathrm{pm})$ and smaller $\nu \mathrm{C}_{(5)}-\mathrm{N}_{(1)}$ stretching frequency (ca. $960 \mathrm{~cm}^{-1}$ ) found in this molecule, when compared with the corresponding values in both 1-phenyltetrazole and 5-chloro1-phenyltetrazole $\left(135.3 \mathrm{pm}\right.$ and ca. $1205 \mathrm{~cm}^{-1}$ and $135.7 \mathrm{pm}$ and ca. $1240 \mathrm{~cm}^{-1}$, respectively [39]).

\subsection{UV irradiation experiments $(\lambda>235 \mathrm{~nm})$}

UV irradiation $(\lambda>235 \mathrm{~nm})$ of the matrix isolated PT monomers led to fast consumption of the compound $(\sim 50 \%$ in $5 \mathrm{~min}$ ) and appearance of bands due to photochemical products. The results are summarized in Figs. 3 and 4 and Table 2. Fig. 3 shows, in a schematic way, the reaction paths leading to the different observed photoproducts, proposed taking into consideration the analysis of the spectroscopic results, supported by calculations and previously available experimental data on putative photoproducts. The suggested band assignments are summarized in Table 2. A complete list of calculated frequencies and intensities for the observed photoproducts and other relevant chemical species is provided as Supporting Information (Tables S4-S17).
If the photochemistry of PT is analyzed in terms of general reactions, it can cautiously be compared with the photochemistry of 1-methyl-1,4-dihydro-5H-tetrazol-5-thione (MTT), which was studied previously [29]. The main photochemical processes occurring in the latter compound, subjected to the same experimental conditions, are basically: (a) ejection of molecular nitrogen, giving 1-methyl- $1 H$-diazirene-3-thiol; (b) tetrazole ring-opening, leading to methyl isothiocyanate and azide; (c) simultaneous elimination of $\mathrm{N}_{2}$ and sulphur, with production of $\mathrm{N}$-methylcarbodiimide; and (d) loss of CS, producing the intermediate 1-methyl-1,2-dihydrotetrazete, which further gives methyldiazene and $\mathrm{N}_{2}$. In the case of PT, the observed photochemical reactions correspond to processes equivalent to reaction paths (a) and (b) observed for MTT: molecular nitrogen elimination, leading to 1-phenyl-diazirin-3-one (Pathway 1), and ring-opening reactions, producing isocyanates and azides (Pathways 2 and 3; see Fig. 3). Very interestingly, these reactions are distinct from the main thermal fragmentation reaction of PT, where CO is produced. Indeed, heating of the compound in the gas phase, prior to deposition of the matrix, led to appearance in the spectrum of the deposited gas of the characteristic narrow band of monomeric carbon monoxide, at $2135 \mathrm{~cm}^{-1}$. Together with $\mathrm{CO}$, the main thermal reaction shall lead to products that are weak IR absorbant species, since no other bands due to thermal fragmentation of PT could be identified in the spectra (there is also spectroscopic evidence of thermal production of a minor amount of phenylisocyanate, through



proposed pathway corresponding to the preferred gas-phase thermal $(\Delta)$ fragmentation is also indicated. 


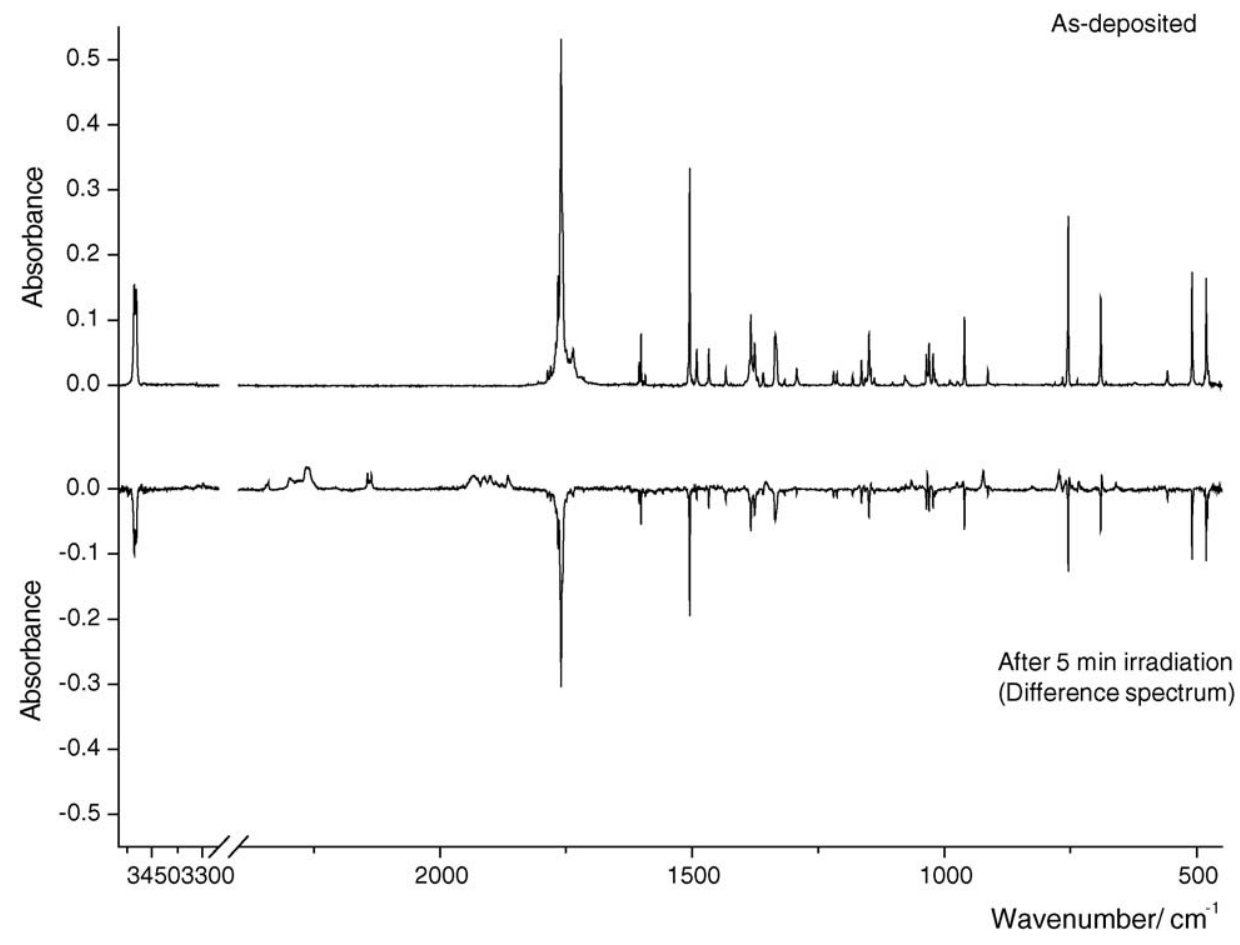

Fig. 4. Infrared spectra of PT isolated in an argon matrix (as-deposited matrix) and after 5 min of irradiation $(\lambda>235 \mathrm{~nm})$ through the outer KBr window of the cryostat (difference spectrum: irradiated matrix minus as-deposited matrix).

observation of a weak band at the expected position of the intrinsically very intense band-mark of this compound, near $2260 \mathrm{~cm}^{-1}$. However, taking into consideration the relative calculated intensities for this band- $1757 \mathrm{~km} \mathrm{~mol}^{-1}$-and for the $\mathrm{CO}$ band $-89.2 \mathrm{~km} \mathrm{~mol}^{-1}$ - and the experimentally observed intensity ratio-ca. $1 / 2$-this must correspond to a much less efficient reaction channel for thermal fragmentation of PT). Both 1-phenyl-1,2-dihydrotetrazete and phenyldiazene, which can be obtained from 1-phenyl-1,2-dihydrotetrazete by molecular nitrogen elimination, satisfy the criterion of being weak IR absorbants (see Tables S5 and S17-Supporting Information). It can then be proposed that the preferred thermal fragmentation channel of PT consists in direct elimination of $\mathrm{CO}$, with production of 1-phenyl-1,2-dihydrotetrazete, which quickly eliminates $\mathrm{N}_{2}$, yielding phenyldiazene as the final product. This is the equivalent process to the photochemical reaction channel (d) of MTT [29], above mentioned.

Photochemical Pathway 1 in PT corresponds to a [3+2] pericyclic molecular nitrogen elimination reaction, which leads to production of two conformers of 1-phenyl-diaziridin-3-one (I and II). The calculations predict these two conformers separated by $14.5 \mathrm{~kJ} \mathrm{~mol}^{-1}$, with form (I) corresponding to the conformational ground state. In this form, the phenyl group and the diaziridinone-ring hydrogen atom are trans to each other (CCNC and $\mathrm{O}=\mathrm{C}-\mathrm{NH}$ dihedral angles equal to 41.6 and $-90.5^{\circ}$ ). In conformer II (cis), these angles are 36.2 and $77.2^{\circ}$, respectively. The most intense bands of the diaziridinone isomers correspond to the $\nu \mathrm{C}=\mathrm{O}$ and $\nu \mathrm{C}-\mathrm{N}$ antisymmetric stretching vibrations and the $\gamma(\mathrm{C}-\mathrm{H}$ ring 1$)$ rocking mode. All the bands corresponding to these vibrations could be identified in the spectra: for conformer I, they are observed at 1931.9/1926.0/1877.8/1874.3 (site-split Fermi resonance doublet resulting from interaction of $\nu \mathrm{C}=\mathrm{O}$ with the $\nu \mathrm{C}-\mathrm{N}$ first overtone), 964.5/962.8 ( $\nu \mathrm{C}-\mathrm{N})$ and $771.0 \mathrm{~cm}^{-1}[\gamma(\mathrm{C}-\mathrm{H}$ ring 1$)]$ (calculated values: 1931.2, 945.5 and $756.2 \mathrm{~cm}^{-1}$ ), while for conformer II the corresponding bands are observed at 1913.1/1899.4/1865.8/1862.7, 924.0/922.8 and $695.3 \mathrm{~cm}^{-1}$ (calculated values: 1921.2, 910.0 and $694.2 \mathrm{~cm}^{-1}$ ). Other theoretically predicted intense bands of the diaziridinone could also be observed in other spectral regions, corresponding to a total of 22 different experimentally observed vibrations (see Table 2).

The bands due to the diaziridinone were in fact relatively easy to identify, since they only increased of intensity during the first half of the irradiation time (i.e., until ca. 30 min of irradiation; in fact, the bands due to the less stable conformer start to decrease before this time). Indeed, this is the only directly observable product whose bands exhibit this behavior, which is consistent with the fact that this compound can further react during irradiation in a significant extent and with a rate constant of the same order of magnitude of that associated with the reaction leading to its formation. Two different pathways can be postulated for photodegradation of the diaziridinone, the first one yielding phenyldiazene plus $\mathrm{CO}$, and the second one leading to production of phenylnitrene and isocyanic acid (with the nitrene undergoing subsequent ring expansion to 1-aza-1,2,4,6cycloheptatetraene [43-45]). The characteristic behavior of the intensity changes with time of irradiation noticed for the bands ascribed to the diaziridinone is especially evident in the $\nu \mathrm{C}=\mathrm{O}$ region, where the bands ascribed to this species were shown only to increase of intensity in the first $30 \mathrm{~min}$ of irradiation, while the bands observed in the same spectral region at 1894.2 and $1889.8 \mathrm{~cm}^{-1}$, ascribed to 1-aza-1,2,4,6-cycloheptatetraene, 
Table 2

Experimental and calculated [DFT/B3LYP/6-311++G(d,p)] frequencies and intensities of the observed photoproducts of PT

\begin{tabular}{|c|c|c|c|c|c|}
\hline \multirow[t]{2}{*}{ Molecule } & \multicolumn{2}{|l|}{ Calculated } & \multicolumn{2}{|c|}{ Observed frequency $\left(\mathrm{cm}^{-1}\right)$} & \multirow[t]{2}{*}{ Approximate Description } \\
\hline & Frequency $\left(\mathrm{cm}^{-1}\right)$ & Intensity $\left(\mathrm{km} \mathrm{mol}^{-1}\right)$ & Reference $^{b}$ & This study & \\
\hline \multicolumn{6}{|c|}{ 1-Phenyl-diarizirin-3-one } \\
\hline II & 3296.9 & 9.1 & & $3241.9 / 3214.9$ & $\nu \mathrm{N}-\mathrm{H}$ \\
\hline \multirow[t]{2}{*}{ I } & 1931.2 & 669.7 & & $1931.9 / 1926.0$ & $\nu \mathrm{C}=\mathrm{O}$ FR $2 \times \nu \mathrm{C}-\mathrm{N}$ as. \\
\hline & & & & $1877.8 / 1874.3$ & \\
\hline I & 1599.2 & 18.1 & & 1589.9 & $v(\mathrm{C}-\mathrm{C}$ ring 2$)$ \\
\hline II & 1597.2 & 12.9 & & 1589.9 & $v(\mathrm{C}-\mathrm{C}$ ring 2$)$ \\
\hline I & 1486.4 & 36.2 & & 1488.3 & $\delta(\mathrm{C}-\mathrm{H}$ ring 2$)$ \\
\hline II & 1484.1 & 34.2 & & 1488.3 & $\delta(\mathrm{C}-\mathrm{H}$ ring 2$)$ \\
\hline II & 1242.9 & 48.8 & & 1240.9 & $\nu \mathrm{N}-\mathrm{C}$ (inter-ring) \\
\hline I & 1236.2 & 54.1 & & 1237.9 & $\nu \mathrm{N}-\mathrm{C}$ (inter-ring) \\
\hline II & 1041.4 & 19.6 & & 1043.6 & $\delta(\mathrm{C}-\mathrm{H} \operatorname{ring} 3)$ \\
\hline I & 945.5 & 140.1 & & $964.5 / 962.8$ & $\nu \mathrm{C}-\mathrm{N}$ as. \\
\hline II & 915.6 & 61.4 & & 927.9 & $\gamma(\mathrm{C}-\mathrm{H}$ ring 3$)$ \\
\hline II & 910.0 & 109.8 & & $924.0 / 922.8$ & $\nu \mathrm{C}-\mathrm{N}$ as. \\
\hline I & 903.9 & 19.6 & & 912.3 & $\gamma(\mathrm{C}-\mathrm{H}$ ring 3$)$ \\
\hline II & 762.3 & 45.9 & & $772.9 / 772.6$ & $\gamma(\mathrm{C}-\mathrm{H}$ ring 2$)$ \\
\hline I & 762.1 & 43.4 & & $772.9 / 772.6$ & $\delta($ ring 3$)$ \\
\hline II & 758.7 & 0.8 & & n.o. & $\delta(\operatorname{ring} 3)$ \\
\hline I & 756.2 & 51.9 & & 771.0 & $\gamma(\mathrm{C}-\mathrm{H}$ ring 1$)$ \\
\hline II & 694.2 & 55.2 & & 695.3 & $\gamma(\mathrm{C}-\mathrm{H}$ ring 1$)$ \\
\hline I & $691 \cdot 8$ & $24 \cdot 1$ & & n.o. ${ }^{d}$ & $\gamma(\mathrm{C}-\mathrm{H}$ ring 2$)$ \\
\hline I & 585.3 & 18.7 & & $583.5^{\mathrm{e}}$ & $\gamma \mathrm{C}=\mathrm{O}$ \\
\hline & 2214.5 & 279.9 & 2135 & $2143.7 / 2139.6 / 2137.8^{g}$ & $\nu \mathrm{N}=\mathrm{N}^{+}=\mathrm{N}^{-}$as. \\
\hline & 1277.3 & 9.1 & 1263 & $1278.6 / 1266.9$ & $\nu \mathrm{N}=\mathrm{N}^{+}=\mathrm{N}^{-} s$ \\
\hline & 1166.9 & 267.8 & 1146 & $1169.4 / 1159.7 / 1154.1$ & $\delta \mathrm{NH}$ \\
\hline & 523.5 & 22.3 & 533 & $537.2^{\mathrm{h}}$ & $\gamma \mathrm{N}=\mathrm{N}^{+}=\mathrm{N}^{-}$ \\
\hline \multicolumn{6}{|c|}{ Phenylazide } \\
\hline & 2197.1 & 772.6 & $2165 / 2157 / 2137$ & $2143.7 / 2139.6 / 2137.8^{\mathrm{g}}$ & $\nu \mathrm{N}=\mathrm{N}^{+}=\mathrm{N}^{-}$as. \\
\hline & & & $2128 / 2112 / 2102$ & & \\
\hline & & & 2087 & & \\
\hline & 1600.2 & 47.4 & 1598 & 1597.0 & $v(\mathrm{C}-\mathrm{C}$ ring 2$)$ \\
\hline & 1488.8 & 72.6 & $1496 / 1491$ & 1457.7 & $\delta(\mathrm{C}-\mathrm{H}$ ring 2$)$ \\
\hline & 1315.3 & 147.9 & 1398 & 1349.2 & $v \mathrm{~N}=\mathrm{N}^{+}=\mathrm{N}^{-} s$ \\
\hline & 1309.0 & 13.9 & 1337 & 1311.2 & $\delta(\mathrm{C}-\mathrm{H}$ ring 1$)$ \\
\hline & 1299.0 & 32.2 & $1305 / 1298$ & 1296.5 & $v(\mathrm{C}-\mathrm{C}$ ring 3$)$ \\
\hline & 1129.3 & 26.3 & $1136 / 1131$ & 1130.2 & $\nu \mathrm{C}-\mathrm{N}$ \\
\hline & 1085.2 & 8.6 & 1076 & 1075.8 & $\delta(\mathrm{C}-\mathrm{H} \operatorname{ring} 3)$ \\
\hline & 810.3 & 43.5 & 810 & 801.9 & $\delta \mathrm{CNN}$ \\
\hline & 747.2 & 68.7 & 751 & 733.9 & $\gamma(\mathrm{C}-\mathrm{H}$ ring 1$)$ \\
\hline & 683.6 & 26.6 & 687 & 660.7 & $\tau($ ring 1$)$ \\
\hline & 670.7 & 26.7 & 670 & 652.6 & $\delta \mathrm{N}=\mathrm{N}^{+}=\mathrm{N}^{-}$ \\
\hline & 509.6 & 15.4 & 537 & $537.2^{\mathrm{h}}$ & $\gamma \mathrm{N}=\mathrm{N}^{+}=\mathrm{N}^{-}$ \\
\hline \multicolumn{6}{|c|}{ 1-Aza-1,2,4,6-cycloheptatetraene } \\
\hline & 1913.1 & 202.2 & 1895 & 1894.2/1889.8 & $\nu \mathrm{C}=\mathrm{C}=\mathrm{N}$ as. \\
\hline & 1339.8 & 19.8 & 1348 & 1349.0 & $\delta(\mathrm{CH} 1)$ \\
\hline
\end{tabular}


Table 2 (Continued)

\begin{tabular}{|c|c|c|c|c|c|}
\hline \multirow[t]{2}{*}{ Molecule } & \multicolumn{2}{|l|}{ Calculated } & \multicolumn{2}{|c|}{ Observed frequency $\left(\mathrm{cm}^{-1}\right)$} & \multirow[t]{2}{*}{ Approximate Description $^{c}$} \\
\hline & Frequency $\left(\mathrm{cm}^{-1}\right)$ & Intensity $\left(\mathrm{km} \mathrm{mol}^{-1}\right)$ & Reference $^{b}$ & This study & \\
\hline & 1301.5 & 3.0 & 1303.4 & $\nu \mathrm{C}=\mathrm{C}=\mathrm{N} s$ & \\
\hline & 1110.9 & 15.2 & $1111 / 1105$ & $1111.0 / 1104.9^{\mathrm{i}}$ & $\delta(\mathrm{CH} 2)$ \\
\hline & 979.7 & 25.6 & 980 & 975.5 & $\nu \mathrm{NC}$ \\
\hline & 951.4 & 3.0 & 952.2 & $\gamma(\mathrm{CH} 1)$ & \\
\hline & 945.7 & 4.5 & 940 & 942.2 & $\gamma(\mathrm{CH} 2)$ \\
\hline & 850.6 & 4.7 & 860.6 & $\delta(\operatorname{ring} 1)$ & \\
\hline & 823.2 & 2.6 & 823.8 & $\delta($ ring 2) & \\
\hline & 754.3 & 62.3 & 748 & 758.7 & $\gamma(\mathrm{CH} 3)$ \\
\hline & 685.0 & 45.5 & 683 & 687.6 & $\delta \mathrm{C}=\mathrm{C}=\mathrm{N}$ \\
\hline & 663.8 & 28.2 & $658 / 650$ & 660.7 & $\tau($ ring $)$ \\
\hline & 595.5 & 10.9 & 580 & $583.5^{\mathrm{e}}$ & $\gamma \mathrm{C}=\mathrm{C}=\mathrm{N}$ \\
\hline \multicolumn{6}{|c|}{ Phenylisocyanate } \\
\hline & 2322.0 & 1839.7 & $\sim 2296 / 2289 / 2266$ & $2296.8 / 2291.9 / 2283.5$ & $\nu \mathrm{NCO}$ as. \\
\hline & & & $\sim 2230$ & $2276.5 / 2267.1 / 2263.1$ & \\
\hline & & & & $2260.6 / 2251.5 / 2231.3$ & \\
\hline & & & & $2229.5 / 2207.2$ & \\
\hline & 1602.3 & 44.4 & & n.o. & $\nu(\mathrm{C}-\mathrm{C}$ ring 2$)$ \\
\hline & 1518.6 & 31.9 & & 1516.8 & $v \mathrm{NCO} s$ \\
\hline & 1452.4 & 10.3 & & 1441.2 & $\nu(\mathrm{C}-\mathrm{C}$ ring 6$)$ \\
\hline & 1290.7 & 4.8 & & $1289.5 / 1285.1$ & $v(\mathrm{C}-\mathrm{C} \operatorname{ring} 3)$ \\
\hline & 1116.2 & 52.5 & & $1111.0 / 1104.9^{i}$ & $\nu \mathrm{C}-\mathrm{N}$ \\
\hline & 1078.0 & 9.7 & & 1064.5 & $\delta(\mathrm{C}-\mathrm{H}$ ring 3$)$ \\
\hline & 904.3 & 5.7 & & n.o. ${ }^{\mathrm{k}}$ & $\gamma(\mathrm{C}-\mathrm{H}$ ring 3$)$ \\
\hline & 750.9 & 63.7 & & 752.5 & $\gamma(\mathrm{C}-\mathrm{H}$ ring 1$)$ \\
\hline & 750.1 & 13.2 & & 747.8 & $\delta(\operatorname{ring} 3)$ \\
\hline & 685.4 & 27.3 & & 687.6 & $\tau($ ring 1$)$ \\
\hline & 623.7 & 26.4 & & 629.8 & §NCO. \\
\hline & 556.0 & 25.1 & & $583.5^{\mathrm{e}}$ & $\gamma \mathrm{NCO}$. \\
\hline
\end{tabular}

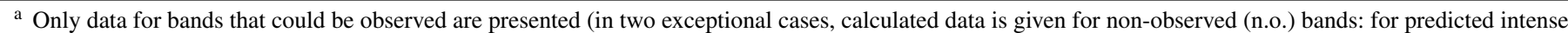

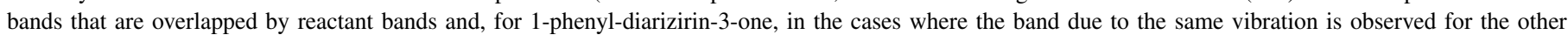
conformer). The full list of calculated frequencies and intensities is provided as Supporting Information (Tables S4-S16).

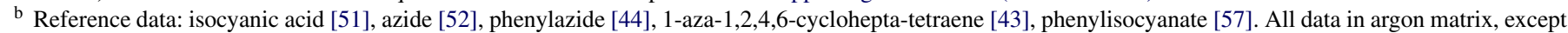
for phenyl azide $\left(\mathrm{N}_{2}\right.$ matrix).

c $\nu$, stretching; $\delta$, bending; $\gamma$, rocking (out of plane bending); FR, Fermi resonance.

d Overlapped with the $756.1 / 754.6 / 752.2 \mathrm{~cm}^{-1}$ multiplet band of PT.

e This band has partial contributions from several photoproducts.

${ }^{\mathrm{f}}$ buried under the intense group of bands due to $\nu \mathrm{NCO}$ as. of phenylisocyanate.

$\mathrm{g}$ This group of bands is assigned to both azide and phenylazide, since it was not possible to discriminate bands due to each molecule (see also text).

$\mathrm{h}$ This band has partial contributions at least from azide and phenylazide.

i Assigned to 1-aza-1,2,4,6-cyclohepta-tetraene, phenylisocyanate and 1-phenyl-diarizirin-3-one (I).

j Overlapped with the $1605.6 / 1601.6 \mathrm{~cm}^{-1}$ bands of PT.

k Overlapped with the $914.2 \mathrm{~cm}^{-1}$ band of PT.

show a continuous growth even for longer irradiation times (Fig. 5).

The CO elimination reaction of the diaziridinone would lead to simultaneous production of phenyldiazene, and it could be expected that these two species interact with each other in the matrix cage where they are formed. Then, the photochemically formed associated CO should absorb at different frequency, when compared with the isolated monomer. In fact, while the characteristic band of the isolated $\mathrm{CO}$ monomer observed in the as-deposited matrix as result of thermal degradation in the gas phase prior to deposition did not increase during the irradiation of the matrix, other features were observed to grow in this spectral region (as expected for associated CO, appearing at higher frequencies and being considerably broader [41]). However, azides formed in Pathways 2 and 3 described below also absorb in this spectral region, and then the photoproduction of $\mathrm{CO}$ from the diaziridinone cannot be established with certainty from the analysis of this spectral region. Moreover, very unfortunately, according to the calculations the compound formed together with $\mathrm{CO}$, phenyldiazene, does not have any strong IR band lying in a clean spectral region (in both possible conformations-see Table S5, Supporting Information). This fact precludes the direct experimental identification of this compound. However, methyldiazene (together with CS) has been previously identified as photoproduct of 1-methyl- $1 \mathrm{H}$-diazirene3-thiol subjected to identical experimental conditions [29] and, thus, the photochemical production of phenyldiazene (and $\mathrm{CO}$ ) in the present case seems very likely.

The second process where the diaziridinone acts as reactant leads to production of isocyanic acid and phenylnitrene. 




Fig. 5. $2350-1800 \mathrm{~cm}^{-1}$ spectral region of the irradiated $(\lambda>235 \mathrm{~nm})$ sample at different times of irradiation and calculated spectra, in this spectral range, for $\mathrm{CO}$, azide (A), isocyanic acid (ICA), phenylazide (PA), phenylisocyanate (PIC), 1-phenyl-diaziridin-3-one conformers [PD(1) and $\mathrm{PD}(\mathrm{II})]$ and 1-aza-1,2,4,6cycloheptatetraene (CHT). Experimental spectra were obtained after 2 (thick solid line), 10 (thin solid line), 30 (dashed) and 60 (dotted) min. of irradiation. Calculated spectra were obtained at the B3LYP/6-31++G(d,p) level of theory and simulated using Gaussian functions centered at the calculated (scaled) frequency and with bandwidth at half height equal to $5 \mathrm{~cm}^{-1}$.

The photochemistry of singlet phenylnitrene is well known [43-47]. It easily undergoes ring expansion to 1-aza1,2,4,6-cycloheptatetraene (the calculated ground state energies for these two species favor the latter compound by ca. $80 \mathrm{~kJ} \mathrm{~mol}^{-1}$-see Tables S9 and S11), whose characteristic bands $[46,47]$ could be clearly identified in the spectra of the irradiated PT Ar-matrix. Particularly noticeable is the intense band-mark associated with the antisymmetric stretching of the ketenimine moiety $(\nu \mathrm{C}=\mathrm{C}=\mathrm{N}$ as. $)$ of 1 -aza-1,2,4,6cycloheptatetraene, observed at ca. $1895 \mathrm{~cm}^{-1}$ [46], but other bands previously described by Huisgen et al. [47] as fingerprints of 1-aza-1,2,4,6-cycloheptatetraene could also be clearly identified in the spectra (Table 2), unequivocally testifying the photoproduction of this species. On the other hand, experimental identification of isocyanic acid is less straightforward, since the most intense bands of this compound [48-51] are nearly coincident with bands due to other photoproducts (see Table 2), in particular phenylisocyanate, which is formed in Pathway 3 (Fig. 3) and, as shown below, is one of the major observed photoproducts.

Pathway 2 represents the cleavage of the tetrazole ring to give isocyanic acid and phenylazide. This is then an alternative path for production of isocyanic acid to that above discussed and, with all probability, it shall correspond to the dominant reaction channel leading to this product. Phenylazide can further react, eliminating molecular nitrogen, to give phenylnitrene and then, again 1-aza-1,2,4,6-cycloheptatetraene. Phenylazide has been previously isolated and irradiated in both argon and nitrogen matrices, and production of 1-aza-1,2,4,6-cycloheptatetraene unequivocally demonstrated [43-45]. The vibrational spectrum of matrix-isolated phenylazide is then well known and its identification could be made here without any difficulty (see Table 2), despite the fact that, in the present case, phenylazide can be expected to interact with isocyanic acid produced in the same matrix cage (see Fig. 6 for the calculated minimum energy structure of the phenylazide:isocyanic acid associate, and Table S17-Supporting Information-for the complete calculated IR spectrum of this species; the associate is a planar species, with the isocyanic acid hydrogen pointing to the nitrogen atom of phenylazide connected to the phenyl ring and one of the ortho hydrogen atoms of the phenyl ring of this latter molecule pointing to the nitrogen atom of isocyanic acid. The associate has then two hydrogen-bond like interactions with calculated NH. . . N and CH. . . N distances of 205.1 and 295.4 pm, respectively). Since the bands assigned to phenylazide still continue to grow after $60 \mathrm{~min}$ of irradiation, it can be concluded that, under the experimental conditions used, phenylazide reacts with

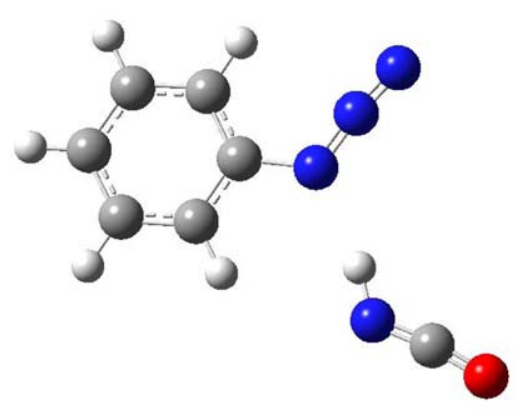

(a)

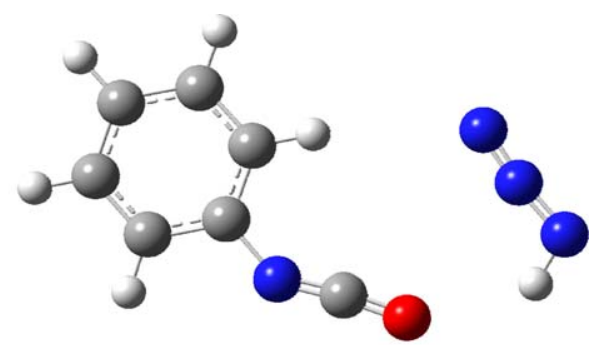

(b)

Fig. 6. Calculated B3LYP/6-31++G(d,p) minimum energy structures of (a) phenylazide/isocyanic acid and (b) azide/phenylisocyanate complexes. 
relatively low efficiency, in particular when compared to PT, being formed faster than it is consumed to yield 1-aza-1,2,4,6cycloheptatetraene (note that the amount of this latter compound formed cannot be used to estimate relative efficiencies of the different processes because it can also be produced in Pathway 1, as described above).

It shall also be noticed that phenylnitrene (in triplet state) could also be previously observed in low temperature matrices as a result of direct photolysis of isolated phenylazide [45]. However, we have no convincing evidence pointing to a direct experimental observation of this species in our spectroscopic data, even when irradiation was undertaken using different wavelength cut-off filters (e.g., 285, 337, 375 and $417 \mathrm{~nm}$ ). The absence of observation of triplet phenylnitrene in the present study may result from the fact that phenylazide and isocyanic acid are produced together and interact in the matrix cage, eventually making inaccessible the pathway which would lead to formation of the triplet phenylnitrene (or, alternatively, favoring its fast decay, once formed, to the reactive singlet state).

Pathway 3 corresponds to tetrazole ring-opening leading to phenylisocyanate and azide as photoproducts (see Fig. 3). There is no indication that these compounds undergo additional reactions. On the other hand, being produced in the same matrix cage they can interact with each other leading to formation of a phenylisocyanate/azide associate. We have undertaken extensive calculations on this associate and found only one minimum in its potential energy surface (double-degenerated by symmetry). The minimum energy structure is depicted in Fig. 6. It is a planar species, with the hydrogen of the azide pointing to the oxygen atom of the phenylisocyanate and one of the ortho hydrogen atoms of the phenyl ring of this latter molecule pointing to the terminal nitrogen atom of the azide. The associate has then two hydrogen bonds (NH. . .O and CH. . .N distances are calculated as 232.7 and $297.8 \mathrm{pm}$, respectively), which form a 10membered ring. The calculated stabilization energy (including zero point energy correction) due to formation of the associate amounts to $-10.10 \mathrm{~kJ} \mathrm{~mol}^{-1}$.

The spectrum of the matrix-isolated azide has been reported previously [52-56]. Himmel et al. [52] described signals at $3317,2135,1263,1146$ and $533 \mathrm{~cm}^{-1}$ as fingerprints of azide. In the present study, all these bands were identified, though as shown in Table 2, they appear at slightly different frequencies, with all probability as a consequence of the interaction of azide with phenylisocyanate. On the other hand, Pritchina et al. [57] have reported the spectrum of phenylisocyanate in solid argon, which in that case resulted from photolysis of benzoylazide. The experimental spectrum of phenylisocyanate is easily identifiable because it shows a very intense multiplet in the $2290-2260 \mathrm{~cm}^{-1}$ region, due to the $\nu \mathrm{NCO}$ antisymmetric stretching vibration, that clearly dominates the spectrum. According to the theoretical predictions, the intensity of such unusually intense band represents about $90 \%$ of the total intensity of the spectrum of phenylisocyanate (see Tables S13 and S15, Supporting Information).

It is worth to point out that, as mentioned before, the $v(\mathrm{NCO})$ asymmetric stretching of isocyanic acid is also expected to absorb in this spectral region. However, reaction Pathway 3 appears to be the dominant one and phenylisocyanate shall thus be produced in relatively larger amount than isocyanic acid. Besides, the predicted IR intensity for the $\nu$ (NCO) asymmetric stretching in phenylisocyanate is by far larger than in isocyanic acid $\left(1840 \mathrm{~km} \mathrm{~mol}^{-1}\right.$ versus $\left.994 \mathrm{~km} \mathrm{~mol}^{-1}\right)$. In view of these data, it can confidently be stated that the profile of the complex band in the $2290-2260 \mathrm{~cm}^{-1}$ region is essentially due to the absorption of phenylisocyanate. Detailed analysis of the band as a function of the time of irradiation shows that the component at $2263 \mathrm{~cm}^{-1}$ follows a slightly different pattern of variation (Fig. 5) pointing to an additional contribution to this wavenumber of an absorption from other photoproduct, which cannot be other than isocyanic acid (this wavenumber closely match the previously reported one for matrix-isolated isocyanic acid [51]: $2259 \mathrm{~cm}^{-1}$ ).

The $v$ NCO antisymmetric stretching vibration is strongly involved in Fermi resonance interactions, whose profile was found to closely follow that observed for isolated phenylisocyanate monomer [57] (see Table 2). This means that the interaction between phenylisocyanate and azide in the associate is not strong enough to introduce dramatic changes in the vibrational potential of phenylisocyanate. Support to this conclusion can also be found by comparing the spectrum of the azide/phenylisocyanate complex (Table S15) with that of the free phenylisocyanate monomer shown in Table S13: the average relative shift in the band maximum wavenumbers upon complexation is as low as $0.86 \%$.

Other less intense bands, appearing in the $1550-550 \mathrm{~cm}^{-1}$ range, could also be assigned to phenylisocyanate, all of them correlating well with both the calculated spectrum for the azide/phenylisocyanate complex and the experimental data reported by Pritchina et al. [57] (see Table 2).

It is also worth noticing that UV irradiation of isocyanates (and also isothiocyanates), has also been reported to induce partial isomerization to the corresponding cyanates (thiocyanates) [58-62]. We tried then to found any experimental evidence of phenylcyanate and cyanic acid in the spectra of the irradiated matrices. However, we were unable to identify a band that could be unequivocally ascribed only to one of these molecules, which seems to indicate that they were not formed (at least in detectable amounts). In the case of cyanic acid, the absence of any band that could be assigned to the $\nu \mathrm{OH}$ stretching vibration (which, in the present case, should appear in a clean spectral region) is a strong indication of the absence of this species in the matrix.

A final note shall be made relatively to the energetic of the primary photochemical processes. Besides irradiation at $\lambda>235 \mathrm{~nm}$, experiments were made using less energetic radiation, using different cut-off filters, from $\lambda>417 \mathrm{~nm}$ to $\lambda>285 \mathrm{~nm}$. Under all these conditions, the compound was found to be photostable. The minimum energy required to trigger the photochemistry of PT was then shown to be within the $420-510 \mathrm{~kJ} \mathrm{~mol}^{-1}$ range. Such range of energies is of the same order of magnitude of the sum of bond energies typical of $\mathrm{C}-\mathrm{N}$ and $\mathrm{N}-\mathrm{N}$ bonds (276 and $193 \mathrm{~kJ} \mathrm{~mol}^{-1}$, respectively [63]). 


\section{Conclusion}

In this work, the structure, vibrational properties and photochemistry $(\lambda>235 \mathrm{~nm})$ of 1-phenyl-tetrazolone have been studied, for the compound isolated in solid argon. It was found that only one tautomer of this molecule (1-phenyl-1,4-dihydro- $5 \mathrm{H}$ tetrazol-5-one) contributes to the spectrum of the as-deposited matrix, indicating that, in the gaseous phase, only this tautomer exists. After UV irradiation of the matrix, three different pathways could be identified, all of them corresponding to cleavage of the tetrazole ring. The identification of the photoproducts was carried out taking into account both the DFT/B3LYP/6-311++G(d,p) calculated spectra for different putative products and the available literature data on those compounds. The following primary photoproducts could be identified in the matrices after irradiation: Pathway 1: two conformers of 1-phenyl-diaziridin-3-one; Pathway 2: phenylazide and isocyanic acid; Pathway 3: azide and phenylisocyanate. Secondary products resulting from Pathways 1 and 2 could also be identified. These are: 1-aza-1,2,4,6-cycloheptatetraene and associated carbon monoxide. The additional production of cyanic acid and phenyl cyanate by isomerization of isocyanic acid and phenylisocyanate looks improbable under the experimental conditions used. The observed photochemical processes are distinct from the preferred thermal fragmentation channel, where $\mathrm{CO}$ is produced together with a weak IR absorbant species, with all probability phenyldiazene (with 1-phenyl-1,2-dihydrotetrazete as possible intermediate).

\section{Acknowledgements}

The authors acknowledge the Portuguese Science Foundation (FCT - POCTI/QUI/59019/2004 and POCTI/QUI/58937/2004) and FEDER for financial support. A.G.-Z. thanks FCT (Grant SFRH/BPD/11499/2002), CONICET and the Argentinian Agencia Nacional de Promoción Científica y Tecnológica (PICT 13080). I.D.R. acknowledges FCT for the Grant SFRH/BPD/1661/2000. L.F. is grateful to FCT for grant SFRH/BD/17945/2004.

\section{Appendix A. Supplementary data}

Supplementary data associated with this article can be found, in the online version, at doi:10.1016/j.jphotochem.2005.08.021.

\section{References}

[1] T. Mavromoustakos, A. Kolocouris, M. Zervou, P. Roumelioti, J. Matsoukas, R. Weisemann, J. Med. Chem. 42 (1999) 1714.

[2] J.H. Toney, P.M.D. Fitzgerald, N. Groversharma, S.H. Olson, W.J. May, J.G. Sundelof, D.E. Vanderwall, K.A. Cleary, S.K. Grant, J.K. Wu, J.W. Kozarich, D.L. Pompliano, G.G. Hammond, Chem. Biol. 5 (1998) 185.

[3] Y. Hashimoto, R. Ohashi, Y. Kurosawa, K. Minami, H. Kaji, K. Hayashida, H. Narita, S. Murata, J. Cardiovasc. Pharm. 31 (1998) 568.

[4] A. Desarro, D. Ammendola, M. Zappala, S. Grasso, G.B. Desarro, Antimicrob. Agents Chemother. 39 (1995) 232.

[5] Y. Tamura, F. Watanabe, T. Nakatani, K. Yasui, M. Fuji, T. Komurasaki, H. Tsuzuki, R. Maekawa, T. Yoshioka, K. Kawada, K. Sugita, M. Ohtani, J. Med. Chem. 41 (1998) 640.
[6] A.D. Abell, G.J. Foulds, J. Chem. Soc. Perkin Trans. 117 (1997) 2475.

[7] G. Sandmann, C. Schneider, P. Boger, Z. Naturforsch. C 51 (1996) 534.

[8] K. Noda, Y. Saad, A. Kinoshita, T.P. Boyle, R.M. Graham, A. Husain, S.S. Karnik, J. Biol. Chem. 270 (1995) 2284.

[9] H. Singh, A.S. Chawla, V.K. Kapoor, D. Paul, R.K. Malhotra, Prog. Med. Chem. 17 (1980) 151

[10] T.L. Shih, M.R. Candelore, M.A. Cascieri, S.-H.L. Chiu, L.F. Colwell Jr., L. Deng, W.P. Feeney, M.J. Forrest, G.J. Hom, D.E. Maclntyre, R.R. Miller, R.A. Stearns, C.D. Strader, L. Tota, M.J. Wyvratt, M.H. Fisher, A.E. Weber, Bioorg. Med. Chem. Lett. 9 (1999) 1251.

[11] R.J. Mathvink, J.S. Tolman, D. Chitty, M.R. Candelore, M.A. Cascieri, L.F. Colwell, Jr., L. Deng, W.P. Feeney, M.J. Forrest, G.J. Hom, D.E. MacIntyre, R.R. Miller, R.A. Stearns, L. Tota, M.J. Wyvratt, H. Fischer, A.E. Weber, in: F. Ahmed, E.C. Breinlinger, B.C. Follows, W.B. Geiss (Eds.), Potent, Selective and Orally Bioavailable 3-Pyridylethanolamine $\beta 3$ Adrenergic Receptor Agonists Possessing a Thiazole Benzenesulfonamide Pharmacophore, vol. 4, no, 48, Albany Molecular Research, Inc. Technical Reports, 220th American Chemical Society National Meeting, Washington, D.C., 20-24 August, 2000, Medicinal Chemistry Department, Albany Molecular Research, Inc, Albany, NY 12212-5098, 28 pp.

[12] R.J. Mathvink, J.S. Tolman, D. Chitty, M.R. Candelore, M.A. Cascieri, L.F. Colwell Jr., L. Deng, W.P. Feeney, M.J. Forrest, G.J. Hom, D.E. MacIntyre, R.R. Miller, R.A. Stearns, L. Tota, M.J. Wyvratt, H. Fischer, A.E. Weber, Bioorg. Med. Chem. Lett. 10 (2000) 1971.

[13] J.Y.L. Chung, G.J. Ho, M. Chartrain, C. Roberge, D. Zhao, J. Leazer, R. Farr, M. Robbins, K. Emerson, D.J. Mathre, J.M. McNamara, D.L. Hughes, E.J.J. Grabowski, P.J. Reider, Tetrahedron Lett. 40 (1999) 6739.

[14] W. Ishikawa, M. Fujiwhara, T. Kojima,T. Endo, K. Kato, United States Patent no. 4289847.

[15] S.P. Burns, P.S. Khandhadia, "Nonazide gas generant compositions". United States Patent no. US5872329.

[16] S.C.S. Bugalho, E.M.S. Maçôas, M.L.S. Cristiano, R. Fausto, Phys. Chem. Chem. Phys. 3 (2001) 3541.

[17] S.C.S. Bugalho, A.C. Serra, L. Lapinski, M.L.S. Cristiano, R. Fausto, Phys. Chem. Chem. Phys. 4 (2002) 1725.

[18] J.W. Bats, Acta. Crystallogr. B 32 (1976) 2866.

[19] W.C. McCrone, D. Grabar, E. Lieber, Anal. Chem. 23 (1957) 543.

[20] N.V. Putten, D. Heijdenrijk, H. Schenk, Cryst. Struct. Commun. 3 (1974) 321.

[21] R. Goddard, O. Heinemann, C. Krüger, Acta. Cryst. C53 (1997) 590.

[22] R.N. Butler, V.C. Garvin, H. Lumbroso, C. Liègeois, J. Chem. Soc. Perkin Trans. II (1984) 721.

[23] C. Zhaoxu, X. Heming, J. Mol. Struct. (Theochem.) 453 (1998) 65.

[24] I.R. Dunkin, C.J. Shields, H. Quast, Tetrahedron 45 (1989) 259.

[25] Y.B. Chae, K.S. Chang, S.S. Kim, The Daehan Hwak Hwoejee 11 (1967) 85.

[26] G. Maier, J. Eckwert, A. Bothur, H.P. Reisenauer, C. Schmidt, Leibigs Ann. (1996) 1041.

[27] A. Awadallah, K. Kowski, P. Rademacher, J. Heterocycl. Chem. 34 (1997) 113.

[28] A. Gómez-Zavaglia, I.D. Reva, L. Frija, M.L. Cristiano, R. Fausto, J. Phys. Chem. A 109 (2005) 7967.

[29] A. Gómez-Zavaglia, I.D. Reva, L. Frija, M.L. Cristiano, R. Fausto, J. Mol. Struct., in press.

[30] I. Dunkin, Spectrochim. Acta 42 (1986) 649.

[31] M.L.S. Cristiano, R.A.W. Johnstone, J. Chem. Soc. Perkin 2 (1997) 489.

[32] M.L.S. Cristiano, R.A.W. Johnstone, J. Chem. Res. (1997) S164-S165.

[33] I. Reva, S. Stepanian, L. Adamowicz, R. Fausto, J. Phys. Chem. A 105 (2001) 4773.

[34] M. Frisch, G. Trucks, H. Schlegel, G. Scuseria, M. Robb, J. Cheeseman J., V. Zakrzewski, J. Montgomery, R. Stratmann, K. Burant, S. Dapprich, J. Millam, A. Daniels, K. Kudin, M. Strain, O. Farkas, J. Tomasi, V. Barone, M. Cossi, R. Cammi, B. Mennucci, C. Pomelli, C. Adamo, S. Clifford, J. Ochterski, G. Petersson, P. Ayala, Q. Cui, K. Morokuma, D. Malick, A. Rabuck, K. Raghavachari, J. Foresman, J. Cioslowski, J. Ortiz, A. Baboul, B. Stefanov, G. Liu, A. Liashenko, P. Piskorz, I. Komaromi, R. Gomperts, R. Martin, D. Fox, T. Keith, M. Al-Laham, C. 
Peng, A. Nanayakkara, M. Challacombe, P. Gill, B. Johnson, W. Chen, M. Wong, J. Andres, C. Gonzalez, M. Head-Gordon, S. Replogle, J. Pople, Gaussian 98, Revision A.9; Gaussian Inc.: Pittsburgh, PA, 1998.

[35] A.D. Becke, Phys. Rev. A. 38 (1988) 3098.

[36] C.T. Lee, W.T. Yang, R.G. Parr, Phys. Rev. B 37 (1988) 785.

[37] P. Csaszar, P. Pulay, J. Mol. Struct. (Theochem.) 114 (1984) 31.

[38] J.H. Schachtschneider, Technical Report, Shell Development Co., Emeryville, CA, 1969.

[39] S.C.S. Bugalho, L. Lapinski, M.L.S. Cristiano, L.M.T. Frija, R. Fausto, Vibrat. Spectrosc. 30 (2002) 213.

[40] S. Lopes, A. Gómez-Zavaglia, L. Lapinski, N. Chattopadhayay, R. Fausto, J. Phys. Chem. A 108 (2004) 8256.

[41] S. Lopes, A. Gómez-Zavaglia, L. Lapinski, R. Fausto, J. Phys. Chem. A 109 (2005) 5560.

[42] K. Honda, K. Furukawa, J. Mol. Struct. 735-736 (2005) 11.

[43] O.L. Chapman, J.-P. Le Roux, J. Am. Chem. Soc. 100 (1978) 282.

[44] I. Dunkin, Spectrochim. Acta 42 (1986) 649.

[45] J.C. Hayes, R.S. Sheridan, J. Am. Chem. Soc. 112 (1990) 5879.

[46] S. Otsuka, A. Nakamura, T.J. Yoshida, Organometallic Chem. 7 (1967) 339.

[47] R. Huisgen, D. Vossius, M. Appl, Chem. Ber., 91 (1958) 1; R. Huisgen, D. Vossius, M. Appl, Chem. Ber., 91 (1958) 12.

[48] V.E. Bondybey, J.H. English, C.W. Mathews, R.J. Contolini, J. Mol. Spectrosc. 92 (1982) 431.
[49] M.E. Jacox, D.E. Milligan, J. Chem. Phys. 40 (1964) 2457.

[50] S. Raunier, T. Chiavassa, A. Allouche, F. Marinelli, J.-P. Aycard, Chem. Phys. 288 (2003) 197.

[51] J.H. Teles, G. Maier, B. Hess, L. Schaad, M. Winnewisser, B. Winnewisser, Chem. Ber. 122 (1989) 753.

[52] H. Himmel, M. Junker, H. Schnöckel, J. Chem. Phys. 117 (2002) 3321.

[53] G.C. Pimentel, S. Charles, K. Rosengren, J. Chem. Phys. 44 (1966) 3029.

[54] D. Milligan, M. Jacox, J. Chem. Phys. 41 (1964) 2838.

[55] C. Moore, K. Rosengren, J. Chem. Phys. 44 (1966) 4108.

[56] W. Zhizhong, J. Mol. Struct. (Theochem.) 434 (1998) 1.

[57] E.A. Pritchina, N.P. Gritsan, A. Maltsev, T. Bally, T. Autrey, Y. Liu, Y. Wang, J.P. Toscano, Phys. Chem. Chem. Phys. 5 (2003) 1010.

[58] J.R. Durig, J. Sullivan, D. Durig, S. Cradock, Can. J. Chem. 63 (1985) 2000.

[59] R.G. Lett, W.H. Flygare, J. Chem. Phys. 47 (1967) 4730.

[60] R.F. Curl Jr., V.M. Rao, K.V.L.N. Sastry, J.A. Hodgeson, J. Chem. Phys. 39 (1963) 3335.

[61] J. Koput, Chem. Phys. Lett. 242 (1995) 514.

[62] R. Fausto, I.D. Reva, L. Lapinski, Abstracts of the XX IUPAC Symposium on Photochemistry, Granada, 2004, pp. 280.

[63] R. Chang, Chemistry, eighth ed., McGraw Hill, New York, 2005 (chapter 9.10). 